\title{
Implementing the Community Care (Direct Payments) Act: Will the Supply of Personal Assistants meet the Demand and at what Price?
}

\author{
PETER SCOURFIELD* \\ * Department of Social Work and Social Policy, Anglia Polytechnic University, East Road, \\ Cambridge CB1 1PT \\ email: p.scourfield@apu.ac.uk
}

\begin{abstract}
Direct payments are becoming an important means by which any disabled person can arrange their care in ways that give them more choice and control over how they are supported. A key part of this new freedom is the ability to employ personal assistants (PAs) on terms laid down by the direct payments user. While endorsing the basic principles underpinning direct payments, this article raises questions over whether the employment market in suitably skilled and competent PAs has been sufficiently well researched. For example, with demand set to grow, will there be an adequate supply of reliable workers to employ? It is possible that raised expectations will not be able to be met adequately. The article also raises questions about regulation and training, particularly in relation to how best to ensure that the needs of vulnerable people are met, that risk is managed effectively and that the principle of leaving key decision making with the employer is retained.
\end{abstract}

Issues around direct payments have generated an enormous amount of debate and discussion among disabled people, social workers, carers, politicians, policy makers and academics. The discussion has been joined from a range of different perspectives (Spandler, 2004). Several interrelated themes and overlapping strands to the debate have emerged. Some aspects of the debate appear to be 'settled', while others continue to be contested and problematised. This article will argue that the discussions have been clearer on ends - that is to say, choice, control and independent living - than the means to achieve those ends. The achievement of choice, control and independent living depends, to a great extent, on there being a firm market for personal assistants willing and able to do the necessary work to achieve those ends.

To create the context for this article, I will separate out the discussion into two broad strands. The first focuses on the broader political, ideological and policy context. The second is more concerned with examining the various 'ground level' issues of putting policy into practice. The focus of this article falls mainly 
within the second strand, highlighting as it does several key issues surrounding the employment of personal assistants. However, such issues are complex and cannot be discussed in isolation. Consequently, in the first part I will briefly aim to outline key aspects of the wider debate. It is proposed that the hegemonic character of the 'transformative' discourse that has emerged around direct payments has largely led to the silencing of critiques, usually by the construction of such critiques as being reactionary. This process is neither in the interest of direct payments users nor their personal assistants. Necessary questions about risk have been omitted.

\section{Political, ideological and policy considerations}

This is a large, complex area which can only be briefly touched on here. For a more detailed historical account of how direct payments have become policy, see Glasby and Littlechild (2002). Spandler (2004) provides a critical discussion of the various strands in the political and ideological context. Nevertheless, it would not be an overstatement to say that, in the UK, both politically and ideologically, the case was made for direct payments and the argument won over a decade ago (Bristenden, 1998; Morris, 1993; Oliver and Sapey, 1999; Priestley, 1999). The Community Care (Direct Payments) Act 1996 overturned the prohibition placed on local authorities by the National Assistance Act 1948 on providing cash payments to disabled people. The system of social care developed in post-war Britain largely under the control of bureau-professionals (for a discussion of the 'bureau-professional' see Clarke et al., 1994). ${ }^{1}$ The subordinated position of disabled people was underlined by a system which arranged services for them based on assessment and service availability. The introduction of direct payments delivered a symbolic message to disabled people (Adams, 2002). By giving ground on a basic principle of the National Assistance Act and all that that piece of legislation represented in terms of old-fashioned Fabian welfarism, the government could demonstrate that it was listening to the views of disabled people, particularly the Independent Living Movement. ${ }^{2}$ The same government introduced The Carers (Services and Recognition) Act 1995 the previous year. This too was an act of symbolic importance in that the government was saying in law for the first time that it recognised the existence of carers. Beyond their symbolic value, however, both of these two acts could arguably be said to represent only a qualified form of empowerment (Jack, 1995; Adams, 2003). Neither radically altered the basic needs-based/means-tested, character of the British social welfare system. In both cases, the disabled person or carer is required to submit to an official assessment of eligibility by a bureau professional. The services that may flow are largely means-tested, resource constrained and limited. However, this is not to downplay the importance of either development to those affected by them. Many have argued that the greater choice and control allowed by direct payments has brought about an enhanced citizenship status for service users within a 'citizen-the-consumer' framework (Rummery, 2002). The two pieces 
of legislation mark out two poles of an overarching debate that has intensified in recent years. The issue goes much deeper than a clash of opinions between the disabled rights movement and the carers' movement; it raises important issues of citizenship, rights and power (Rummery, 2002). It could more properly be read as a battle over how disability is constructed and, as such, needs to be located in the context of the social model/medical model dichotomy (Drake, 1999; Swain et al., 2003). While the carers' movement has raised its profile and gained both recognition and rights by emphasising the burdensome nature of care, the disabled rights movement has sought to challenge the very discourse of care which constructs the receiver of care as both passive and dependent (Morris, 1993; Oliver and Sapey, 1999; Shakespeare, 2000). At the same time, another key strand in this debate is raised by those who have examined the blurred boundaries between informal care and paid care as work (Ungerson, 1997, 1999; Lewis, 2000). This, in turn, taps into a set of wider feminist analyses: both of care relations and the exploitation of women in labour markets (Orme, 2001). ${ }^{3}$ This clash of conflicting and essentially contradictory discourses appears some way from coming to an acceptable resolution.

Having finally given way on the principle of providing cash rather than services in kind, government has needed remarkably little persuasion to expand direct payments from a limited, discretionary scheme to something much wider and obligatory in a comparatively short time period. When the Community Care Act (Direct Payments) 1996 came into force in 1997, it 'allowed' local authorities to assess a person as needing services, and then give that person a cash payment in order to purchase their own services. The scheme was introduced first for younger disabled people, but has subsequently been extended to those aged over 65 . The Carers and Disabled Children Act 2000 extended entitlement to direct payments to include 16 and 17 year olds with a disability and parents of disabled children. In 2003 new regulations were introduced which were designed to further increase take up. ${ }^{4}$

Both disabled groups and central government appear to be equally impatient about the slow rate of progress by local authorities in improving take up among service users. However, this does not mean there is congruity of objectives between the two groups. In its broader context, Spandler claims that the history of direct payments comprises 'a complex confluence of new right, New Labour and welfare user ideologies and demands' (2004: 190).

New Labour's enthusiasm for promoting the take up of direct payments fits comfortably with an approach to social welfare based on consumerism, autonomisation and responsibilisation (Rose, 1999; Adams, 2003). By transferring more control over and responsibility for decision making to the disabled person, the progression to direct payments can be analysed within the changing discourses on risk, wherein it is claimed that collectivised responsibility for health and welfare has given way to the individualisation of risk and the 'double movement' of 
autonomisation and responsibilisation (Beck, 1992; Parton, 1996; Lupton, 1999; Rose, 1999; Edwards and Glover, 2001; Boyne, 2003). Simon Heng, a disabled writer, articulates this. He says: 'What I am finding out is that direct payments also means more responsibilities, risks and problems to solve. Which means more worries.' He continues: 'Although there is often help available, you have responsibility for recruiting and selecting your carers. This can take time.' (2004: 20-21) This latter point will be discussed in more depth later.

The Blair government's commitment to direct payments was underlined when the take up of direct payments was made a performance target for social services: 'From April 2003 councils have a duty to make direct payments where individuals consent to and are able to manage them, with or without assistance' (DH, 2003a: 114).

The Department of Health states that, in England, average take up for 200203 was 23 people receiving direct payments per 100,000-population aged 18 or over. The target set out in the Framework indicates that, while 30 or above is acceptable, ultimately figures of 150 people per 100,000 would represent 'very good' performance. To further assist take up, the Direct Payments Development Fund was set up in 2003 to make grants to voluntary support organisations.

All of these developments have taken place within a discourse in which direct payments have been represented and talked about using the language of empowerment, rights, emancipation, independence, choice and control. A speech given by the Health Minister in 2004 is indicative. He says

Direct payments really do change lives.... People's personal ambitions, their desires and hopes and dreams, should be the centre of planning the support they need; in that way we liberate people, we transform lives, we make things possible that previously seemed impossible.

Few, if any, significant counter discourses challenge the right of disabled people to receive direct payments. Pearson (2000) located the development of direct payments in two discourses: market and social justice, the incongruities of which necessarily cause tensions. These tensions raise questions about the degree of user empowerment that might realistically accrue from direct payments, largely because of structural barriers. Stainton (2002), choosing to focus more on the 'pivotal role' played by social workers, also questioned whether direct payments - even with the support of social workers - could realise the degree of autonomy implied by the social justice discourse. These concerns do not appear to have unduly troubled either government or user groups. The hegemonic character of the emancipatory discourse has generally served to shut down most critiques until comparatively recently. Spandler argues that this 'may be partly due to the relatively recent take-up in the UK compared with the US and Canada, where more critiques and debates have emerged' (2004: 194). Such questions that have been raised have either focused on issues of mental capacity, concerns about cost, and questions about possible inequity between direct payments users and those not on direct payments. 
Whether the principle of direct payments is a 'good idea' or not is no longer under debate among policy makers or most user groups, although whether direct payments represent a step towards independent living or are a refinement of community care has been raised by writers (Morris, 1997, 2003; Priestley, 1999). This draws our attention to the process whereby government has effectively sat its 'market-consumer' discourse on the disabled movement's 'social rights discourse', producing a powerful hybridisation but one riddled with tensions (Pearson, 2000; Spandler, 2004). Whether direct payments, in their present form, are as 'transformative' as is claimed is therefore debatable (Heng, 2004; Spandler, 2004). Nevertheless, a point has been reached where, with growing pressure both from below and above, the demand for direct payments is set to accelerate. The expansion of direct payments comes at a time when certain fundamental issues are still unresolved.

\section{Social care practice, financial and administrative considerations}

The latter part of the 1990s to date has seen the discussions on directs payments become more focused on take up rates, investigating barriers to wider take up, identifying the necessary support systems and concentrating on how to get the system to work effectively for all the potential user groups: that is to say, people with learning disabilities, older people, people with mental illness, carers and ethnic minority groups across the board as well as younger disabled people who have been in the vanguard of the movement. There is a large body of literature that has examined these and a range of other practice, financial and administrative issues (Clark et al., 2004; Davidson and Luckhurst, 2002; Glasby and Littlechild, 2002; Glendinning et al., 2000a; Hasler et al., 1999; Hasler, 2003a, 2003b; Jones, 2000; Leece, 2002; Maglajlic et al., 2000; Spandler, 2004; Witcher et al., 2000). It is not my intention to provide a detailed analysis of all these issues. However, I will set out a brief outline of some of the main themes.

Slow rate of take up has been an ongoing theme. Hasler refers to a 'culture of conservatism' (2003a: 5) within local authorities. Many local authorities have been slow to disseminate appropriate information to potential users. They have not involved service users and they have been slow in setting up the necessary 'infrastructure': for example, support systems (Clark et al., 2004; Witcher et al., 200o). Another important theme that has emerged is the role played by frontline workers, particularly care managers. Hasler found that: 'Although there is often an enthusiasm for the aims of direct payments among care managers, there is also widespread anxiety, and uncertainty about putting them into practice' (2003a: 3). Witcher et al. (2000) found that, in the context of existing heavy caseloads, care managers were concerned about the possible demands on their time, especially in the absence of a supporting organisation. They also found that a lack of knowledge and experience among social services staff at all levels created a reluctance to engage with direct payments. This was further evidenced by Clark et al. (2004). Dawson (2000) found that some care managers were withholding 
information about direct payments from their clients. Research by Clark and Spafford (2001) which focused on the barriers facing older people in the take up of direct payments also found that some care managers were uncertain or confused about the 'willing and able' criteria, There was a lack of time for care managers to explain the scheme properly and, significantly, there were concerns over protecting users from risk.

Most care managers had immediately identified clients for whom the scheme 'would be ideal' - mainly older people whom they felt liked to be in control and were more assertive about their likes and dislikes. Some formed a judgement from their own perceptions of the older person's 'mental capability'. For example, several care managers felt that people with mental health problems would have too many difficulties managing the scheme to be considered 'able'. Others judged ability to use the scheme by the older person's understanding of charging policies. Yet others felt it inappropriate to offer the scheme to very old people (Clark and Spafford, 2001: 28).

However, it would be misleading to portray care managers as simply paternalistic or negative in their approach (Stainton, 2002). Clark et al. (2004), for example, reported the great sense of satisfaction that care managers experienced when direct payments had been successfully implemented.

Direct payments for people with learning disabilities have their own history. Northfield states: 'Early indications were that people with a learning disability were being excluded from some schemes' (2001:3). This is because care managers were making insufficient allowance for any assistance that might be available. However, groups such as Values into Action have worked to develop ways in which people with a learning disability can 'direct' their choices and preferences rather than having complete control over the process. In this respect, the concept of the 'circle of support' has become an established means of providing the necessary assistance.

Similar concerns about 'capacity' have been expressed among mental health service users. Davidson and Luckhurst discovered that some potential direct payments users with mental health problems had 'the fear that being assessed as "mentally able to manage a direct payment" may then be seen as in conflict with "needing services or support"' (2002: vi). This led to the question: 'How can we get a needs assessment which shows both that we need a significant amount of support, and that we are "able to manage" a direct payment (the "able" versus "unwell" dilemma)?' (2002: 15). Davidson and Luckhurst proposed that either a recovery or a social model of disability offered a better assessment framework than the traditional medical model in this respect.

Care managers face dilemmas and tensions in trying to balance the assessment of eligibility with the protection of vulnerable people from risk, together with the requirement to promote empowerment through direct payments (George, 2001; Stainton, 2002). The introduction of direct payments has 
created additional (often unacknowledged) ambiguities over who is accountable for managing risk.

The findings from Witcher et al. (2000) revealed that care managers 'without exception' identified the need for more training, information and support. This finding is supported by Clark and Spafford (2001) and Clark et al. (2004). Dawson's study (2000) indicated that successful implementation required that staff at all levels of the organisation were committed.

Beyond care management, concerns about both the likely cost of direct payments schemes and the lack of adequate funding have also been raised as a possible barrier to implementation (Hasler et al., 1999). Witcher et al. (2000) found that funding restraints proved a barrier to implementation, particularly where money was not ring-fenced. Several studies have shown how important it is to have proper support systems in place (Hasler et al., 1999; Kestenbaum, 2001; Clark et al., 2004). Hasler found difficulties occurred when: 'Restricted budgets have led to restricted levels of funding for support schemes (2000a: 4). However, despite these concerns, researchers have been keen to stress that, in the mid to longer term, budgetary gains are possible (Hasler, 200ob; Witcher et al., 2000; Clark et al., 2004).

This has not been an exhaustive analysis of the practice, financial and administrative issues raised in connection with direct payments, by any means. However, it has been shown that, 'on the ground', there is a clear and marked determination among groups working with and on behalf of all potential direct payments users to meet the challenges, overcome the barriers and maximise take up as far as possible. There now appears to be substantial momentum in getting direct payments more established and not just as an alternative to conventional social care. There is evidence of a growing movement wishing to extend the scope of direct payments still further, to include health as well as social care (Glendinning et al., 2000a, 200ob).

\section{Potential demand, recruitment and employment issues}

In a speech in 2004 Stephen Ladyman, the Health Minister, argued:

We have changed the law - direct payments are no longer just a power that local councils have they are a duty. And it's a duty to make direct payments, not just to offer them. This means that at every assessment and at every review, direct payments should be discussed - and as a real, achievable option for everyone, whatever their disability or age. (Speech made 26 January 2004 to Direct Payments regional conferences)

Local authorities must now offer direct payments in order to meet performance targets (Department of Health, 2003a). In addition, the pressures from service users can be expected to increase with greater awareness through formal and informal networks. Furthermore, it is reasonable to suggest that, as local authorities and care managers in particular become more experienced and confident with 
direct payments, many of the barriers touched on above will be overcome, again leading to wider take up (Clark et al., 2004). Demand should grow significantly.

While the very nature of direct payments gives flexibility to the service user in how they spend the money, the demand for personal assistants in particular must be set to increase. Figures from 2002-03 (DH, 2003a) show that the estimated number of people in receipt of direct payments was 9,600 (7,000 in the 18-64 age group and 2,700 sic in the 65 and over group), a rise of 53 per cent on the previous year. The early years of direct payments have the feel of a 'cottage industry' about them. The development of direct payments has been progressed by initiatives starting up at different rates in different localities, slowly increasing as local authorities become better organised, more confident and with information more effectively disseminated. Pearson refers to a 'culture of localized care markets' (2000: 459). The increase from 2001-02 to 2002-03 is striking and might tell us something about latent demand. The logic of further extending take up across the country is that direct payments must surely become a mass industry, national in scope.

It is difficult to predict with any great certainty what the demand for personal assistants will be. Obviously, it should not be assumed that every person in receipt of a social services care package will opt for a direct payment in lieu of services. Older people are the biggest consumers of social care. When this group was researched by Hasler et al. in 1999, it was found that, 'A significant proportion of older people may, initially at least, be unsure about the suitability of this option' (Hasler, 2003b). Yet studies such as those by Clark and Spafford (2001) and Clark et al. (2004) suggest that, with the appropriate level and type of support, many of the potential barriers can be overcome. Therefore, to be in a particular categoryfor example, to have Alzheimer's disease or a learning disability - cannot exclude a person from consideration. Basically, decisions must be taken on a case-by-case basis (Northfield, 2001)

According to the Department of Health (2003b), there were an estimated 1.68 million clients receiving services in 2002-03. Community based services including home care, day care, meals, direct payments, equipment and adaptations - were provided to 1.4 million clients during the year. Bearing in mind that some people receive 'mixed support packages' - direct payments together with another community-based service - the number of directs payments clients in 2002-03 as a percentage of the overall number of those receiving community based services works out roughly at about 0.65 per cent. There are a number of variables - not least the ease or otherwise of recruiting suitable staff - that will influence the rate of future take up. It is therefore difficult to make a forecast about demand with any great accuracy. However, if we saw a 53 per cent increase from 2001-02 to 2002-03 when there were still many unresolved issues and where, arguably, circumstances were less conducive than they are now, then one should expect the demand curve to continue to rise quite steeply. Assuming councils in 
England were able to achieve the targets of 150 per 100,000 set in 2003 , then the number of people in receipt of direct payments would increase approximately sixfold to around 60,000. If we assume (and this might be seen as conservatively by some) that in the next five years, demand for direct payments rises to 10 per cent of those eligible for services, then this translates to roughly 150,000 people. This in turn suggests that tens of thousands of personal assistants would be needed. If direct payments really do take off in the way that many envisage, then in the next decade this could see the demand for this kind of worker rise to the order of hundreds of thousands. It is important to understand this in the context of ongoing recruitment and retention problems in the wider home care sector (DH, NHC and UKHCA, 2004). The Chief Executive of Action on Elder Abuse, talking in May 2004 about the domiciliary care sector, said:

It's cracking at the seams. It can't take any more clients. It's easier for someone looking for employment to take a job working in a supermarket rather than working in domiciliary care. The money is better and it's a lot less stressful. (Observer, 9 May 2004)

To date, very little research has been carried out into the recruitment and employment of personal assistants. What there has - for example, see Ungerson $(1997,1999)$ - raises several questions. Rummery observes:

There are some problems with this kind of scheme (direct payments), such as the underdevelopment of a proper 'market' in personal assistants and other service providers to enable direct payments users to exercise options of choice and exit, the lack of training and career development for personal assistants. (2002: 178)

It was proposed earlier that the dominant discourse surrounding direct payments emphasises empowerment, control and choice. The following quotation from Glendinning et al. (2000a) is indicative:

I have control over who, what and when. Just everything. I make the decisions and have the final say-so, it rests with me. I'm treated as a person now, as an individual. (User 32)

Given the upbeat, optimistic and 'transformative' nature of these and similar messages, a shortage of reliable and competent personal assistants could lead to unrealistically high expectations being frustrated as well as, in some cases, an enhanced risk of abuse. The question, therefore, is not simply whether a workforce will be there in sufficient numbers, but how can it be ensured that such a workforce is competent, capable, trustworthy and able to meet the needs of a diverse but vulnerable group.

There are several ways that somebody with a direct payment can recruit a personal assistant. The three most common are: to become a direct employer; to use a 'third party scheme' which is brokered through an organisation such as a local Centre for Independent Living; or to use a care agency.

Some agencies are prepared to pitch their fees for carers/personal assistants at whatever the level of the direct payment is. However, recruiting from an agency 
is probably less likely to offer the flexibility and control afforded by other more individualised recruitment strategies. For example, most of the research shows that people using direct payments have valued having the total control over whom they employ as their personal assistant, together with the continuity that comes with this (see, for example, Dawson, 2000; Glendinning et al., 2000a). Using an agency can weaken the level of control a person has and raises the likelihood of personal assistants being changed. On the wider issue of the levels at which direct payments are costed, Glendinning et al. found that the levels of direct payments failed to:

recognise and reflect the costs of providing more skilled or intensive health-related assistance. As a result, those disabled people who had the most extensive or complex needs felt particularly disadvantaged when recruiting personal assistants, because they were unable to offer rates of pay which they felt would be commensurate with the level of expertise or responsibility they expected of their personal assistants. (2000a: 16)

Generally, the research by Glendinning et al. confirms the fear that recruitment is hampered by the low rates of pay that potential employers are forced to offer because of the level of direct payment given to them. The research by Clark et al. into the use of direct payments for older people found

The majority of our participants used their payments to employ PAs. Finding PAs was almost universally cited as a problem as it is by other user groups ... However, it can be particularly difficult for people who have only a small number of hours of employment to offer. (2004: 15)

As indicated earlier, there are ongoing problems faced by home care providers in finding sufficient numbers of workers willing to work in the domiciliary care sector (DH, NHC and UKHCA, 2004). In their research into domiciliary care providers, Matosevic et al. found that, 'Most respondents had experienced difficulties in recruiting suitable care staff ( 75 per cent) and nearly a third rejected at least half of their applicants' (2001: 20).

They found that the three biggest problems cited were: unsuitable applicants (37.5 per cent), competition from other providers (30.4 per cent) and insufficient applicants (26.8 per cent). While it might be argued that a personal assistant and a domiciliary care assistant are not the same animal, there is sufficient overlapping in job type and function to provoke concern over whether there are enough suitable people 'out there' to satisfy raised demand in the future. One can also speculate about the negative impact the stepping up of personal assistant recruitment might have on that of the domiciliary care providers and the knock-on effect this could have for their clients.

We need to ask what kind of person would want to enter the jobs market as a personal assistant. An extract from a message posted on the NCIL message board reads:

Just what type of person would take up working as a PA, given the pay, unsocial hours, lack of support, lack of training and given the attitude that despite providing a service to the 
community, to fellow human beings they appear to rank lower than a domestic cleaner within community care, let alone a shelf stacker in the commercial sector? (5 February 2004)

This is just one view, although it could be reasonably assumed that in making the choice to become a personal assistant, pay, status and career development would not top the list of desiderata. Contrasting the job of personal assistant with other forms of paid care work, Ungerson argues that the occupation of personal assistant is essentially:

'unorganised and particular' ... There may be reasons why individuals seek out an occupation that is unorganised and particular. These may be to do with the job itself: because it is unmanaged, except directly by the employer, precisely because it allows for permeable boundaries between paid work and friendship, normally involves working for a few people, and can mean working for an employer over a long period of time in an intense and intimate fashion. It may also be the context of lack of organisation which attracts labour that wishes to work in a flexible, fragmented and possibly invisible way. Finally, there may be labour market related reasons, to do with the availability of alternative low paid and uncredentialised work. (1999: 598)

Ungerson's research was admittedly small-scale (a sample of fewer than ten) and was carried out at a time when the use of direct payments to employ relatives was not allowed; however, the broad hypothesis would seem to be a reasonable one. Motivational factors behind wanting to work as a personal assistant are necessarily complex and cannot easily be taken for granted. The conventional assumption would be that someone entering such a line of employment knowingly trades pecuniary advantage for more qualitative emotional/psychological compensations. Consequently, having chosen to pursue such employment, it would surely be important for the personal assistant's sense of job satisfaction that they felt they were 'doing a good job'.

However, following someone's instructions to the letter does not necessarily mean that a personal assistant feels that they are doing a good job, particularly if they have prior experience or training in care. Potential tensions can emerge, posing dilemmas for personal assistants about what course of action they should take. For example, Glendinning et al. (2000a: 16) found this response from a direct payments user:

I don't like the idea of these people who've been told the right way to [do things] ... I want to be treated as a human being and as an employer, not as a person to be cared for or done to. (User 34)

The issue of training is potentially problematic. Glendinning et al. (2000a) found that most employers liked to train their personal assistants themselves and there was evidence of resentment when a personal assistant tried to become 'professionalised' in their approach.

On the other hand, the same study revealed that many personal assistants wanted to have more formal training in key aspects of their job. This was particularly the case when they needed to carry out specialised procedures, 
which either required certain technical skills, the possession of certain medical or nursing knowledge, or both. The ability of personal assistants to perform both social and health care tasks can be seen positively as an important step towards integration at the micro level; however, this further underlines the importance of addressing the training question (Glendinning et al., 2000a, 200ob). Different employers have different attitudes to training: some prefer to do their own training; others have said that they would like to have their personal assistants trained in particular areas of competence, not that such training is always readily available (Glendinning et al., 2000a, Pickard et al., 2003).

The training issue throws up several questions. There are practical considerations such as who pays, who organises and provides it and how to make it accessible to all those who require it. There are also perhaps more problematic issues about who decides about what, if any, training is necessary: the employer, the personal assistant, 'professionals' or regulatory bodies? To extend the right to make decisions about these questions beyond the employer to include professionals, bureaucrats and even the employee in the decision-making process, is arguably to infract a fundamental principle of direct payments.

Such questions point us to the fact that the relationship between the direct payments user and 'the authorities' is both paradoxical and ambiguous. The way officialdom scrutinises what direct payments users do with their money combines both a bureau-paternalist and laissez-faire approach. As a local authority provided service, direct payments are monitored and reviewed like any other service. Service users need to submit their accounts for inspection on a regular basis. This extract from official guidelines illustrates the messages given to service users:

Do not spend your direct payments on something which does not meet your assessed needs. Your local council has the power to require you to repay any money which you do not spend on meeting assessed needs.

Will I need to keep records?

Yes. The money you receive in direct payments is for services to meet your social care needs. It remains public money; it is not yours to spend as you wish. Your local council will require you to account for the money you receive. You will be told what records you need to keep and what information you will be expected to provide. ( $\mathrm{DH}, 2003 \mathrm{~d}$ : 50)

On the other hand, employers are free to employ just about anyone they want as their personal assistant. An employer is not obliged to provide any training for their personal assistant; neither are any particular qualifications or certification required. This is the risk employers take. As Hasler says, 'many current users cherish their right to use informal recruitment and unregulated staff (2003b: 23).

Pickard et al. class personal assistants as 'lay carers' and observe, 'As well as receiving no formal training, the care provided by lay carers (other than parent carers) is not monitored and there is no professional regulation of paid carers' (2003: 91). Personal assistants are exempt from the scope of the General Social Care Council's register of people working in social care (Hasler, 2003b). Direct payments users, as individuals, cannot gain access to the Criminal Records Bureau 
(Vasey, 2002). Also, at the time of writing, personal assistants directly employed by a direct payments user are outside the scope of the proposed Protection of Vulnerable Adults Scheme (DH, 2003c).

A Select Committee on Health found that 'abuse in domiciliary settings is the commonest type of abuse, but the most difficult to combat' (2004: 15). It went on to say:

we are especially concerned that service users may be placed at continuing risk from day to day contact with unregistered care workers, a small minority of whom may be abusive working with them on a one-to one, unsupervised basis. (p. 35)

There is clearly an unresolved contradiction in policy in this area between the sustained promotion of direct payments on the one hand and an unwillingness to bring those employed through direct payments schemes under new regulatory frameworks on the other. The Select Committee (2004: para. 152) is seemingly ambivalent about what should happen. However, should evidence of abusive behaviour by unregulated personal assistants emerge in the future, one wonders whether the victim might, on some level, be held responsible.

Therefore, paradoxically, while the service of direct payments is monitored, reviewed and audited, the actual services purchased with the direct payments are neither monitored nor regulated. The direct payments user is a strange hybrid construction being a 'citizen-as-consumer-as-service-user-as-employer' (see Spandler, 2004: 189). They are both in control and controlled at the same time. They are 'set free' but responsibilised through audit mechanisms. As Power (1994) puts it, 'audit is the control of control' (cited in Rose, 1999: 154).

Given that direct payments are regarded as at least some form of step towards independent living, we must ask how far users of direct payments would or should be prepared to allow outsiders to regulate and control aspects of the individually negotiated contracts. To participate willingly in discussion about training is one thing, to be overridden on the training needs of one's personal assistants is potentially infantilising. Talk of direct payments as empowering would look rather like empty rhetoric. However, this leaves the question of what the personal assistants themselves feel they need. Should the principles of choice, independence and control give an employer the automatic right of veto when people other than themselves identify skills deficits and training needs in their personal assistant? This raises further questions about the employment rights of personal assistants.

Some personal assistants are especially attracted to the informality of the job and value both the absence of regulation and the fact there is no specific qualification requirement (Ungerson, 1999), but there is evidence - see, for example, Glendinning et al. (2000a) and Pickard et al. (2003) - that some personal assistants want formal training qualifications, not only to enhance the quality of the assistance provided but also to improve future career opportunities (Glendinning et al., 2000a). However, a consequence of personal assistants 
being given some form of professional or quasi-professional training is that this can lead to differences in opinion between employers and their personal assistants over what is in the employer's 'best interest'. With training can come the expectation that more complex procedures are carried out, and this in turn can create uncertainty about how to best deal with the additional risks attached to these procedures (Glendinning et al., 2000a). Ironically, having knowledge about empowerment can reveal divergent value positions between employer and personal assistant. Ungerson provides the example of the personal assistant who had been recruited from a voluntary organisation which supported an ideology of empowerment. This particular personal assistant 'reported that she was confused about how far she should encourage her employer to act more independently than he was apparently willing to do' (1999: 589). Ungerson adds that, 'In this case, the quasi-professional PA saw her role as partially educational, leading to personal change on the part of the user/employer' (p. 590).

Whether this is regarded as empowering practice on behalf of a dedicated and enlightened employee or the subtle abuse of power by someone who thinks they know best is a matter of perspective. The issue of how far personal assistants should be encouraged to think for themselves is clearly a matter for the individual employer. However, one assumes that most employers want their assistants to be something more than robots.

The appeal of becoming a personal assistant is more likely to be based on performing a socially necessary job than on factors of pay and conditions: it is, after all, relatively low-paid and low-status work with the likelihood of unsocial hours. There are also no formal career development opportunities. Therefore, we might speculate that, for people to opt for this form of work in large numbers, the sense of 'doing a good job' needs to be both strong and unequivocal. However, some evidence (Ungerson, 1999, Glendinning et al., 2000a) suggests that there are circumstances when it might be difficult for a personal assistant to derive the necessary compensatory satisfaction from doing 'a good job'. This is likely to arise if identified training needs are either contested and go unmet or if training actually leads the personal assistant to challenge their employer's decision making. An employee who believes they are ill-equipped, insufficiently trained and discouraged from using their own initiative might easily lose motivation and experience poor levels of job satisfaction. The reactions of personal assistants to these situations, if and when they occur, will vary depending on the individual, but one might assume that this could create staff retention problems. More worryingly though, such conditions might even create a climate in which incidents of abuse might be more likely, should frustration and resentment build up.

Anticipating the implementation of the Community Care Act (Direct Payments) 1996, Ungerson (1997) characterised the market for personal assistants as a 'flea market'. 
It is argued that both employers and employees in these care relationships are likely to be on low incomes, that the work is likely to be insecure and possibly unregulated, that there might be a problem of labour supply, and that, in the long run, this form of employment might generate hardship for the workers so employed. (1997: 45)

Morris (1997) strongly repudiated the Ungerson paper, arguing the right of disabled people to exert choice and maximise control in their lives. While it was a strong moral and political argument, drawing as it did on the struggle for disabled people to have the right to independent living, it rather skirted around the practical issues raised here. For direct payments to work effectively for larger and larger numbers of disabled people, then there must be a willing, motivated, capable and trustworthy workforce in sufficient supply, so that any disabled person who opts for direct payments can freely select and recruit the personal assistants of their choice. We have reviewed some of the reasons why this may not be the case.

Training is particularly problematic because, self-evidently, personal assistants need to be competent in what they do. Also as Glendinning et al. observe:

Training could also contribute to a more defined career structure, which could help reduce the turnover among assistants who left their disabled employer in order to seek other employment opportunities. (2000a: 29)

The issues here range from the practical considerations of funding and availability, to whether, paradoxically, the 'professionalising' effects of training would shift the balance of power away from employers, placing them more back in the role of care receiver than that of an independently living individual. However, if the power is all in the hands of the employer, this is potentially exploitative of the personal assistant. Managing this power dynamic is a complex challenge. Spandler (2004) cites research from Canada that suggests that the detrimental effects of direct payments on personal assistants should not be underestimated. There is a suggestion that 'multi-stakeholder cooperatives' (p. 205) could be developed to deal with these issues. This would require a high degree of sustained commitment from all concerned, for which there is no obvious precedent.

More research into the recruitment of personal assistants is therefore necessary, both from the perspective of the employer and the employee. A survey of employers carried out in Hampshire, which has one of the highest take up rates of direct payments in England, provides some illustrative data (Hampshire Centre for Independent Living, 2003).

In response to the question, 'Do you find it more or less difficult to recruit staff than you did a year ago?', 30 direct payments users replied 'more difficult', 31 'about the same' and three replied 'less difficult'. 
The reasons given by those who answered 'more difficult' were:

- unsociable hours

- limited hours required - less interest in part-time work

- people not interested in this kind of work anymore

- competition from other sources (for example, supermarkets), other work is available and offers better rates

- people book for interviews but then do not turn up

- shift work and live-in work are less popular.

- hourly rate is too low - people want more pay

- Christmas seasonal work makes it harder to find people at that time

- other agencies offer better wages

- too many agencies

- other companies pay more for less work

- there are more people on direct payments all wanting carers for similar hours

- national economy - less unemployment

- living in a rural area makes it harder to get carers.

These findings suggest that, despite the efforts of support groups, structural characteristics of the wider economy and national and local employment markets play a major part in determining the availability of personal assistants. The author's own small-scale research in Cambridgeshire found that employers were often successful in recruiting trusted care assistants who had originally been introduced as part of their care package. Care agencies looked unfavourably on this 'poaching' of staff, particularly in hard-to-recruit areas.

There are suggestions that certain localities might be harder to recruit in than others (Clark et al., 2004). Regional and/or rural-urban differences in recruitment might be expected to correspond to the specific employment characteristics in those areas. One could also speculate that service users from ethnic minority groups might find their recruiting possibilities outside of family networks more difficult. However, little is currently known about either of these two important areas. This seems to be a further sign that a major policy has been launched in the belief that the workforce will simply 'emerge' on demand.

\section{Conclusion}

This article has explained that both government and user groups agree about the desirability of the direct payments option. It has also outlined how successive government policies have been directed towards both consolidating this policy and ensuring it is implemented as widely as possible. Whether or not direct payments can be seen as a significant step towards independent living or an extra refinement in the marketisation of care remains a matter for debate.

What has also been demonstrated is the determination and resourcefulness of disabled groups in making sure that the many barriers to the take up of 
direct payments are overcome. Studies show numerous examples of local groups developing creative ways for how direct payments are used and supported. The government is funding the works of many groups in this respect, principally through the Direct Payments Development Fund.

Initial take up has been slow. However, pressures from both above (central government) and below (disabled groups) are leading to improved take up rates across the country. Many current users of community care services will probably continue to prefer to have services arranged for them. However, for the reasons outlined in this article, the demand for direct payments is set to accelerate. The substantial increase in the number of people opting for direct payments will mean that many more personal assistants will be needed to meet demand. This article argues that insufficient research has been carried out into this labour market. This is in terms of the numbers, skills and characteristics of those prepared to do the work, and the likely impact the recruitment of personal assistants will have on restricting the supply of care assistants needed to perform care tasks for those vulnerable people not using direct payments, which is already under pressure. Also, will the experience of personal assistants working 'powerlessly', on relatively low pay and often in isolation, be detrimental to the welfare of their employers?

The fact that the market for personal assistants is unregulated is also contentious. The promotion of greater take up has taken place when important questions - such as how effectively to balance the rights of vulnerable people to choice and independence with their right to protection from risk and abuse - are far from resolved.

Raising the issue of whether the government can allow personal assistants employed under direct payments schemes to escape regulation is controversial. Calling for regulation of the sector can be construed as professional encroachment into what is supposed to be in the control of service users and therefore a step back for disabled people's independence. However, the combination of low rates of pay, demanding work, unsocial hours and an unregulated workforce could possibly increase the likelihood of abuse taking place. If such cases occur, then this will raise questions of accountability. If direct payments are to pass choice and control to the employer in any meaningful way, then this should mean the responsibility for risk management goes along with it. This formulation is, however, oversimplistic and therefore points to untested ambiguities and tensions in the relationship between the employer (who is simultaneously the service user), the local authority and, where present, the support organisation.

This article is not intended to undermine the principles of independent living for disabled people; neither is it in any way an expression of pessimism about the ability of different groups of vulnerable people to manage their own affairs when given the opportunity. I do, however, feel that some of the messages especially those from government - about the 'transformative' effects of direct payments are overoptimistic. 


\section{Notes}

1 Clarke et al. (1994) argue that the post-war regime of 'bureau-professionalism' derives from 'Fabian assumptions about the proper combination of professional expertise coupled with the regulatory principles of rational administration as the means of accomplishing social welfare' (p. 22). However, they are at pains to make clear that the managerialist project of the 1980 and 1990 - designed to break the power of the bureau-professionals - should be seen more as part of the ideological assault on state welfare by the New Right rather than a desire to promote the entitlements and empowerment of citizens.

2 For a fuller discussion of the origins and philosophy of the Independent Living Movement see Morris (1993). This text discusses the issue of recruitment of personal assistants (ch. 8). However, it was written before the implementation of direct payments legislation and the sustained promotion of their take up, which has taken place more recently. It does not deal directly with the concerns about the stability and reliability of the employment market in personal assistants.

3 The scope of this article is modest. However, several of the issues touched on cut across a range of larger, more complex debates including the politics of gender, the politics of disability, power in the 'cared for'/carer relationship, and the various ways in which community care has impacted on all those involved. Orme (2001) sets out these interrelated themes clearly and in a way that should enable the reader to locate the issues raised in this article in a range of overlapping debates.

4 The Community Care, Services for Carers and Children's Services (Direct Payments) (England) Regulations which came into force in April 2003 changed the discretionary nature of direct payments. Local authorities now have a duty to make payments to those eligible, if the person consents. That person could either have had their needs assessed, or be a carer whose needs for carers' services have been assessed under section 2 (1) of the CDCA 2000. The new regulations also allow direct payments to be made for the purchase of a residential placement, but limited to a maximum of four weeks in any 12-month period. In addition, an important change has been made to the previous blanket prohibition on the payment of the money to a close relative for their services. Under the 2003 regulations, a direct payment may be used to employ close relatives as personal assistants, even those living in the same household as the cared-for person. In such cases, the local authority needs to satisfy itself that securing the service from such a relative is necessary to satisfactorily meet the person's need for that service.

\section{References}

Adams, R. (2002), Social Policy for Social Work, Basingstoke: Palgrave.

Adams, R. (2003), Social Work and Empowerment, 3rd edn, Basingstoke: Palgrave.

Beck, U. (1992), Risk Society: Towards a New Modernity, London: Sage.

Boyne, R. (2003), Risk, Buckingham: Open University Press.

Bristenden, S. (1998), 'Independent living and the medical model of disability', in T. Shakespeare (ed.), The Disability Reader, London: Cassell.

Clark, H. and Spafford, J. (2001), Piloting Choice and Control for Older People - an Evaluation, Bristol: Policy Press.

Clark, H., Macfarlane, A. and Gough, H. (2004), 'It pays dividends': Direct Payments and Older People, Bristol: Policy Press.

Clarke, J., Cochrane, A. and McLaughlin, E. (1994), Managing Social Policy, London: Sage.

Davidson, D. and Luckhurst, L. (2002), 'Making choices taking control - direct payments and mental health service users/survivors', National Council for Independent Living, London.

Dawson, C. (2000), Independent Successes: Implementing Direct Payments, York: Joseph Rowntree Foundation. 
Department of Health (2003a), 'Social services performance assessment frameworks indicators 2002-2003', Department of Health, London.

Department of Health (2003b), 'Community care statistics 2002-03: referrals, assessments and packages of care for adults, England: national summary', Department of Health, London.

Department of Health (2003c), 'Protection of vulnerable adults scheme: a practical guide', Consultation Draft, December (2003),, Department of Health, London.

Department of Health (2003d), 'A guide to receiving direct payments from your local council', Department of Health, London.

DH, NHC and UKHCA (2004), 'Commissioning home care: changing practice: delivering quality?', Department of Health, National Homecare Council and United Kingdom Home Care Association, London.

Drake, R. (1999), Understanding Disability Policies, Basingstoke: Macmillan.

Edwards, R. and Glover, J. (eds) (2001), Risk and Citizenship, London: Routledge.

George, M. (2001), 'Our way or no way', Community Care; 12 July, pp. 32-33.

Glasby, J. and Littlechild, R. (2002), Social Work and Direct Payments, Bristol: Policy Press.

Glendinning, C., Rummery, K., Halliwell, S., Jacobs, S. and Tyrer, J. (2000a), Buying Independence: Using Direct Payments to Purchase Integrated Health and Social Services, Bristol: Policy Press.

Glendinning, C., Rummery, K., Halliwell, S., Jacobs, S. and Tyrer, J. (20oob), 'Bridging the gap: using direct payments to purchase integrated care', Health and Social Care in the Community, 8: 3, 192-200.

Hampshire Centre for Independent Living (2003), 'Direct Newsletter', March (2003), HCIL, Winchester.

Hasler, F. (2003a), Clarifying the Evidence on Direct Payments into Practice, London: National Council for Independent Living.

Hasler, F. (2003b), 'Making choice a reality', Care and Health, 25 April.

Hasler, F., Campbell, J. and Zarb, G. (1999), 'Direct routes to independence', Policy Studies Institute, www.ncil.org.uk/evidence_paper.asp.

Heng, S. (2004), 'Are direct payments a means to greater independence or a route to a life of more worries?', Community Care, 10 June.

Jack, R. (1995), Empowerment in Community Care, London: Chapman \& Hall.

Jones, R. (2000), Getting Going on Direct Payments, London: Association of Directors of Social Services.

Kestenbaum, A. (2001), 'Older disabled people with ILF extension fund awards', Independent Living Fund, Nottingham.

Ladyman, S. (2004), Speech delivered to the Direct Payments regional conferences by Stephen Ladyman, 26 January, www.dh.gov.uk/NewsHome/Speeches/ SpeechesListSpeechesArticle. Accessed 30.6.2004.

Leece, J. (2002), 'Extending direct payments to informal carers: some issues for local authorities', Practice, 14: 2, 31-44.

Lewis, J. (2000), 'Gender and welfare regimes', in G. Lewis. S. Gewirtz and J. Clarke (eds), Rethinking Social Policy, London: Sage.

Lupton, D. (1999), Risk, New York: Routledge.

Maglajlic, R., Brandon, D. and Given, D. (2000), 'Making direct payments a choice: a report on the research findings', Disability and Society, 15: 1, 99-113.

Matosevic, T., Knapp, M., Kendall, J., Forder, J., Ware, P. and Hardy, B. (2001), 'Domiciliary providers in the independent sector', PSSRU Discussion Paper 1605, Nuffield Institute for Health and Personal Social Services Research Unit.

Morris, J. (1993), Independent Lives: Community Care and Disabled People, Basingstoke: Macmillan.

Morris, J. (1997), 'Care or empowerment? A disability rights perspective', Social Policy and Administration, 31: 1, 54-60.

Morris, J. (2003), 'Community care or independent living?', in N. Ellison and C. Pierson (eds), Developments in British Social Policy, Basingstoke: Palgrave. 
Northfield, J. (2001), BILD Factsheet No. 3, Kidderminster: British Institute of Learning Disabilities.

Observer (2004), 'Scandal of the home-help firms failing Britain's elderly', 9 May.

Oliver, M. and Sapey, B. (1999), Social Work with Disabled People, Basingstoke: Macmillan.

Orme, J. (2001), Gender and Community Care, Basingstoke: Palgrave.

Parton, N. (1996), 'Social work, risk and “the blaming system”', in N. Parton (ed.), Social Theory, Social Change and Social Work, London: Routledge.

Pearson, C. (2000), 'Money talks? Competing discourses in the implementation of direct payments', Critical Social Policy, 20: 4, 459-477.

Pickard, S., Jacobs, J. and Kirk, S. (2003), 'Challenging professional roles: lay carers' involvement in health care in the community', Social Policy and Administration, 37: 1, 82-96.

Power, M. (1994), The Audit Explosion, London: Demos.

Priestley, M. (1999), Disability Politics and Community Care, London: Jessica Kingsley.

Rose, N. (1999), Powers of Freedom, Cambridge: Cambridge University Press.

Rummery, K. (2002), Disability, Citizenship and Community Care, Aldershot: Ashgate.

Select Committee on Health (2004), 'Elder abuse', Second Report of Session 2003-04, Volume 1 , House of Commons, London.

Shakespeare, T. (2000), 'The social relations of care', in G. Lewis. S. Gewirtz and J. Clarke (eds), Rethinking Social Policy, London: Sage.

Spandler, H. (2004), 'Friend or foe? Towards a critical assessment of direct payments', Critical Social Policy, 24: 2, 187-209.

Stainton, T. (2002), 'Taking rights structurally: disability, rights and social worker responses to direct payments', British Journal of Social Work, 32: 751-763.

Swain, J., French, S. and Cameron, C. (2003), Controversial Issues in a Disabling Society, Buckingham: Open University Press.

Ungerson, C. (1997), 'Give them the money: is cash a route to empowerment?', Social Policy and Administration, 31: 1, 45-53.

Ungerson, C. (1999), 'Personal assistants and disabled people: an examination of a hybrid form of work and care', Work, Employment and Society, 13: 4, 583-60o.

Vasey, S. (2002), 'Access to criminal records information', National Centre for Independent Living, London. URL: www.ncil.org.uk.

Witcher, S., Stalker, K., Roadburg, M. and Jones, C. (2000), Direct Payments: the Impact on Choice and Control for Disabled People, Edinburgh: Scottish Executive Central Research Unit. 